\title{
$\alpha$-Azido Ketones, Part 8: Base-Induced Coupling of $\alpha$-Azido Ketones with a 1,2-Diaza-1,3-diene as a Michael Acceptor ${ }^{1}$
}

\author{
Éva Juhász-Tóth, ${ }^{\mathrm{a}}$ Gianfranco Favi, ${ }^{\mathrm{b}}$ Orazio A. Attanasi, ${ }^{\mathrm{b}}$ Attila C. Bényei, ${ }^{\mathrm{c}}$ Tamás Patonay*a \\ a Department of Organic Chemistry, University of Debrecen, Egyetem tér 1, 4032 Debrecen, Hungary \\ Fax +36-52-512744; E-mail: patonay.tamas@science.unideb.hu \\ b Department of Biomolecular Sciences, Section COCON, University of Urbino 'Carlo Bo', Via I Maggetti 24, 61029 Urbino, Italy \\ c Laboratory for X-ray Diffraction, Department of Pharmaceutical Chemistry, University of Debrecen, Egyetem tér 1, 4032 Debrecen, \\ Hungary \\ Received: 18.04.2014; Accepted: 31.05.2014
}

\begin{abstract}
Carbanions generated from various acyclic and cyclic $\alpha$-azido ketones in the presence of bases were reacted with ethyl 3-[(carbamoylimino)amino]but-2-enoate as a Michael acceptor to give the corresponding adducts. The adducts of acyclic azides were unstable and eliminated hydrazoic acid to give the corresponding ethyl 2-[1-[(carbamoylamino)imino]ethyl]-4-oxo-4-phenylbut-2enoates as $(E, E / Z, E)$-diastereomeric mixtures. The relative configuration of these diastereomers was determined by X-ray analysis. Adducts of cyclic $\alpha$-azido ketones were obtained in diastereomerically pure form, with the exception of 2-azidobenzosuberone.
\end{abstract}

Key words: ketones, azides, Michael additions, carbanions, diazadienes

$\alpha$-Azido ketones $\mathbf{1}$ (Scheme 1) are a synthetically valuable group of azides ${ }^{2}$ that exhibit dual reactivity in $\mathrm{C}-\mathrm{C}$ bond formation. The electrophilic carbonyl function provides a target for the attack by carbanions, leading to adducts such as compounds 2 ; this chemistry has been utilized by Langer and co-workers. ${ }^{3}$ On the other hand, $\alpha$-azido ketones with at least one $\alpha$-hydrogen atom show enhanced $\mathrm{C}-\mathrm{H}$ acidity as a result of the anion-stabilizing effect of the azido group. The controlled generation of carbanions 3 and their subsequent trapping by various carbon electrophiles results in the formation of aldol-type products 4 .

We have previously demonstrated that base-induced reactions between $\alpha$-azido ketones $\mathbf{1}$ and simple aldehydes or more complex carbonyl compounds, such as $\alpha$-oxo aldehydes or $\alpha$-oxo esters, provide an efficient method for the preparation of valuable tri- and tetrafunctionalized synthons. ${ }^{4}$ The reaction of $\alpha$-azido ketones with aldehydes has been used successfully by Padwa and co-workers. ${ }^{5} \mathrm{~A}$ similar coupling with in situ generated imines using organocatalysts has also been reported. ${ }^{6}$ Surprisingly, little is known about the reactions of $\alpha$-azido ketones $\mathbf{1}$, acting as carbon nucleophiles, with Michael acceptors. Phenacyl azides have been treated with strongly activated acceptors having two electron-withdrawing groups to give the expected adducts, which, in turn, are capable of eliminating nitrogen under basic conditions and cyclize to pyrroles. ${ }^{7}$

SYNLETT 2014, 25, 2001-2004

Advanced online publication: 28.07 .2014

DOI: 10.1055/s-0033-1338655; Art ID: st-2014-d0332-1

(C) Georg Thieme Verlag Stuttgart · New York

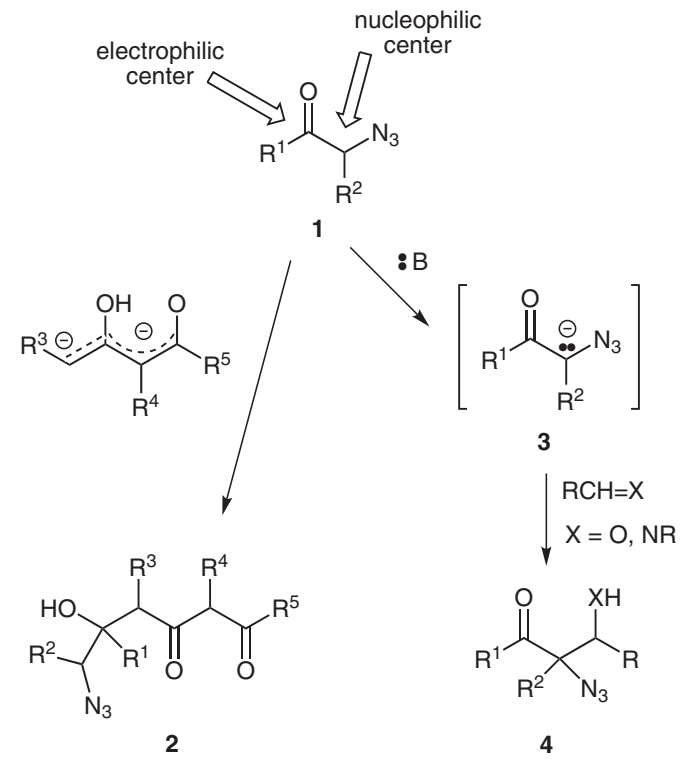

Scheme 1 The reactivity of $\alpha$-azido ketones in $\mathrm{C}-\mathrm{C}$ bond formations

In this contribution, we describe the reaction of $\alpha$-azido ketones 1 with 1,2-diaza-1,3-dienes as Michael acceptors. Attanasi and co-workers have been notably active in the field of 1,2-diaza-1,3-dienes for over thirty years, ${ }^{8}$ and they have demonstrated the utility of these compounds in the construction of a range of heterocyclic systems.

The chemical properties of 1,2-diaza-1,3-dienes are mainly related to the electron-withdrawing effect of the azo group in the heterodiene system. In general, electron-deficient substituents (such as ester or amide groups) on the terminal carbon and/or nitrogen tend to stabilize the heterodiene and enhance its electrophilic character. ${ }^{8}$ 1,2-Diaza1,3-dienes typically undergo regioselective nucleophilic attack on the carbon atom at the 4-position by a variety of carbon or heteroatom nucleophiles to give highly functionalized hydrazone intermediates.

We studied the Michael addition of 2-azido-(4-substituted phenyl)ethanones 5, (adamantan-1-yl)-2-azidoethanone (9), 2-azido-1,2-diphenylethanone (11), 3-azido(thio)chromanones 13 and 14, 2-azidobenzosuberone (15a) to ethyl 3-[(carbamoylimino)amino]but-2-enoate (6) under basic conditions. When we treated 2-azido-(4-substituted 
phenyl)ethanones (5) with 2.0 equivalents of diazadiene $\mathbf{6}$ in the presence of a catalytic amount (10\%) of 1,8-diazabicyclo[5.4.0]undec-7-ene (DBU) in dry tetrahydrofuran at room temperature, we obtained ethyl 2-[1-[(carbamoylamino)imino]ethyl]-4-oxo-4-arylbut-2-enoates 8 in good to excellent yields. Two of the four possible diastereomers were detected and isolated in each case (Scheme 2 and Table 1, entries 1-4). The formation of these $\alpha, \beta$-unsaturated esters could be interpreted in terms of a Michael-type 1,4-addition leading to the $\alpha$-substituted hydrazone intermediates 7 and a subsequent elimination of hydrazoic acid, promoted by the formation of the conjugated double-bond system. This elimination seems to take place very readily. Typically, the ${ }^{1} \mathrm{H}$ NMR signals of the intermediate 7 could be identified in the spectrum of the crude product after the workup, but the signals of adduct 7 disappeared during purification by column chromatography. The only case in which we were able to obtain a small amount of the azide intermediate $7 \mathbf{b}$ in pure form after column chromatography was in the reaction of the 4methyl analogue $\mathbf{5 b}$ (Scheme 2 and Table 1, entry 2).

Table 1 Reactions of 2-Azido-(4-substituted phenyl)ethanones 5ad with Diazadiene 6

\begin{tabular}{|c|c|c|c|c|c|c|c|}
\hline Entry & $\begin{array}{l}\text { Star } \\
\text { mat }\end{array}$ & Base & $\mathrm{R}$ & $\begin{array}{l}\text { Time } \\
\text { (h) }\end{array}$ & $\begin{array}{l}\text { Yield } \\
\text { (\%) of } 7\end{array}$ & $\begin{array}{l}\text { Yield } \\
(\%) \text { of } 8\end{array}$ & $\begin{array}{l}\text { d.r. } 8 \\
(E, E / Z, E)\end{array}$ \\
\hline 1 & $5 a$ & DBU & $\mathrm{H}$ & 1 & 0 & 68 & $60: 40$ \\
\hline 2 & $5 b$ & DBU & $\mathrm{Me}$ & 1 & 7.8 & 57 & $55: 45$ \\
\hline 3 & $5 c$ & DBU & $\mathrm{OMe}$ & 1 & 0 & 44 & $30: 70$ \\
\hline 4 & $5 d$ & DBU & $\mathrm{Cl}$ & 1 & 0 & 76 & $67: 33$ \\
\hline 5 & $5 a$ & $\mathrm{Et}_{3} \mathrm{~N}$ & $\mathrm{H}$ & 44 & $49^{\mathrm{b}}$ & $17^{\mathrm{b}}$ & $80: 20^{\mathrm{b}}$ \\
\hline 6 & $5 c$ & $\mathrm{Et}_{3} \mathrm{~N}$ & $\mathrm{OMe}$ & $60^{\mathrm{a}}$ & $51^{\mathrm{b}}$ & $21^{\mathrm{b}}$ & $79: 21^{b}$ \\
\hline 7 & $5 d$ & $\mathrm{Et}_{3} \mathrm{~N}$ & $\mathrm{Cl}$ & 19 & $49^{\mathrm{b}}$ & $51^{\mathrm{b}}$ & $83: 17^{\mathrm{b}}$ \\
\hline
\end{tabular}

a $77 \%$ conversion.

${ }^{\mathrm{b}}$ Ratio calculated from spectra of the crude product before column chromatography.

The diastereomers $(E, E)-\mathbf{8}$ and $(Z, E)$-8 were separated by column chromatography. X-ray analysis showed that the more soluble, less polar isomer had an $E, E$ relative configuration, whereas the less soluble more polar isomer had a $Z, E$ configuration (Figures 1 and 2). ${ }^{10}$

Crystallization of the more polar diastereomers proved to be extremely difficult, but we finally succeeded in gaining a single crystal from the parent compound 8a. This single crystal was weakly diffracting, resulting in an $\mathrm{R}$ value of $\sim 13 \%$, but this, nevertheless, permitted the assignment of the $Z, E$ relative configuration. Having unequivocally determined these configurations, we were then able to assign the configurations for the remainder of the series on the basis of their characteristic NMR spectroscopic features.

In the ${ }^{1} \mathrm{H}$ NMR spectra (DMSO- $d_{6}$ ) of the more polar $Z, E$ isomers, the 2"-Me signal appeared at a lower field than in<smiles>[R]OC=C(C)/C=C(\C)N=NC(N)=O</smiles><smiles>[R]c1ccc(C(=O)[C@@H](N)[C@H](C(=O)OCC)/C(C)=N/NC(N)=O)cc1</smiles><smiles>[R]OC(=CC(=O)c1ccc(Br)cc1)C(C)=NNC(N)=O</smiles>

$(E, E)-\mathbf{8} \mathbf{a}-\mathbf{d}$<smiles>[R]OC(=O)/C(=C/C(=O)c1ccc([18F])cc1)C(C)=NNC(N)=O</smiles>

$(Z, E)-8 \mathbf{a}-\mathbf{d}$

$$
\begin{array}{c|cccc}
\mathbf{5 , 7 , 8} & \text { a } & \text { b } & \text { c } & \text { d } \\
\hline R & \text { H } & \text { Me } & \text { OMe } & \text { Cl }
\end{array}
$$

Scheme 2 Michael addition of 2-azido-(4-substituted phenyl)ethanones $5 \mathbf{a}-\mathbf{d}$ to diazadiene 6

the corresponding signal for the $E, E$ diastereomers $(\Delta \delta=$ $0.29-0.34 \mathrm{ppm})$. Moreover, the aromatic 2'- and 6'-protons of the $Z, E$ isomers appeared at a higher field than those of the $E, E$ diastereomers; the extent of the shift $(\Delta \delta=0.29-0.34 \mathrm{ppm})$ being quite similar to that observed for the 2 --hydrogens. The ${ }^{13} \mathrm{C}$ NMR spectra also showed some significant differences. A marked downfield shift was observed in the case of the $\mathrm{C}-4$ signals of $E, E$ isomers compared with those of the $Z, E$ isomers $(\Delta \delta=5.8-5.9$ ppm), whereas the signals for $\mathrm{C}-1, \mathrm{C}-2$, and $\mathrm{C}-1$ " of the $E, E$ isomers were also shifted to a higher field.

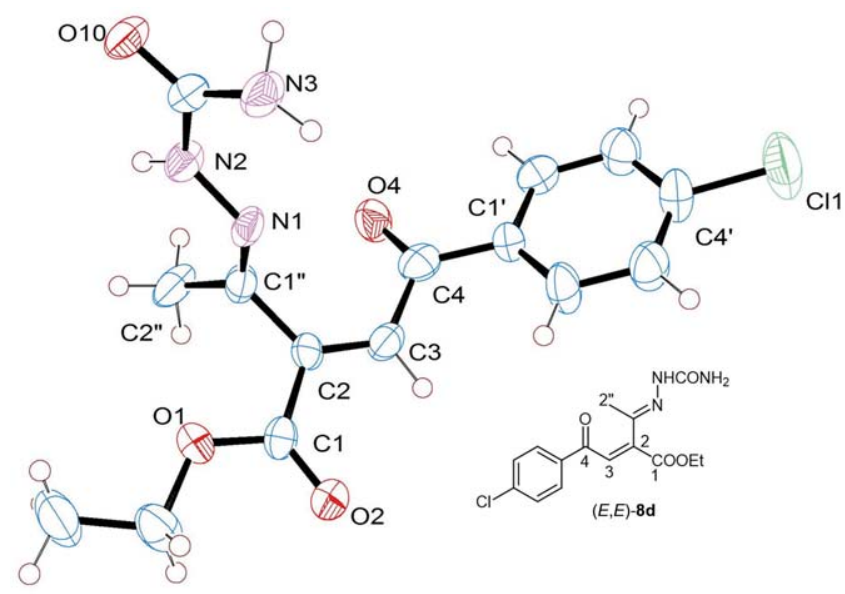

Figure 1 Crystal structure of $(E, E)-\mathbf{8} \mathbf{d}^{10}$ 


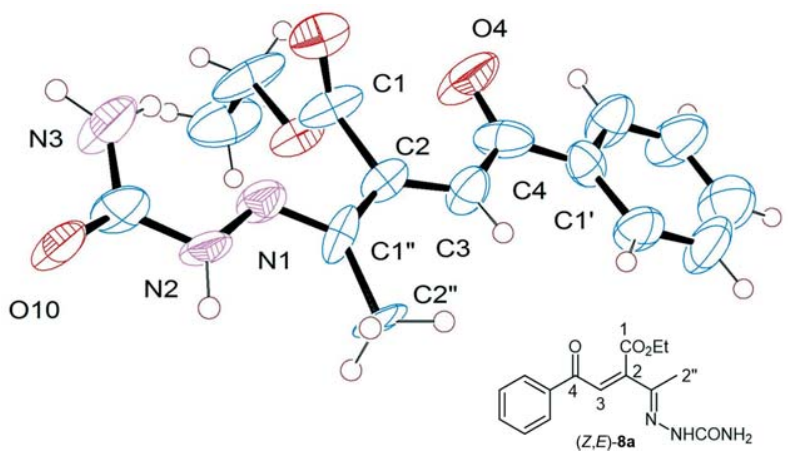

Figure 2 Crystal structure of $(Z, E)-\mathbf{8} \mathbf{a}^{10}$

The effect of the temperature on the reaction was examined in the case of 2-azido-1-(4-methoxyphenyl)ethanonone (5c), but no change in the product ratio was observed when the reaction was performed at $-15^{\circ} \mathrm{C}$ instead of at room temperature. When a catalytic amount of triethylamine was used as base instead of DBU and the reactions of azides $\mathbf{5 a}, \mathbf{5 c}$, and $\mathbf{5 d}$ were performed at $0{ }^{\circ} \mathrm{C}$, the corresponding azide derivatives $7 \mathbf{a}, 7 \mathbf{c}$, and $\mathbf{7 d}$ were obtained in higher yields, as shown by ${ }^{1} \mathrm{H}$ NMR analysis of the crude product (Table 1; entries 5-7). However, our attempts to isolate the azide products 7 in pure form by column chromatography failed and, in all cases, we were only able to isolate mixtures of the azide adducts $7 \mathbf{a}, 7 \mathbf{c}$, and $7 \mathbf{d}$ and the corresponding vinyl esters $8 \mathbf{a}, \mathbf{8 c}$, and $8 \mathbf{d}$ as diastereomeric mixtures. We concluded that the high lability of the Michael adducts prevents their isolation in pure form.

Treatment of 1-(adamantan-1-yl)-2-azidoethanone (9) with 2.0 equivalents of diazodiene 6 in the presence of a catalytic amount of DBU in dry tetrahydrofuran at subambient temperatures gave the Michael addition product, ethyl 4-(adamantan-1-yl)-3-azido-2-[1-[(carbamoylamino)-imino] ethyl]-4-oxobutanoate ( $\mathbf{1 0}$ in diastereomerically pure form and in a good yield (53\%; Scheme 3$)$; no elimination product was detected or isolated. It appears that the presence of an aromatic unit connected to the ketone functionality accelerates the elimination of hydrazoic acid.
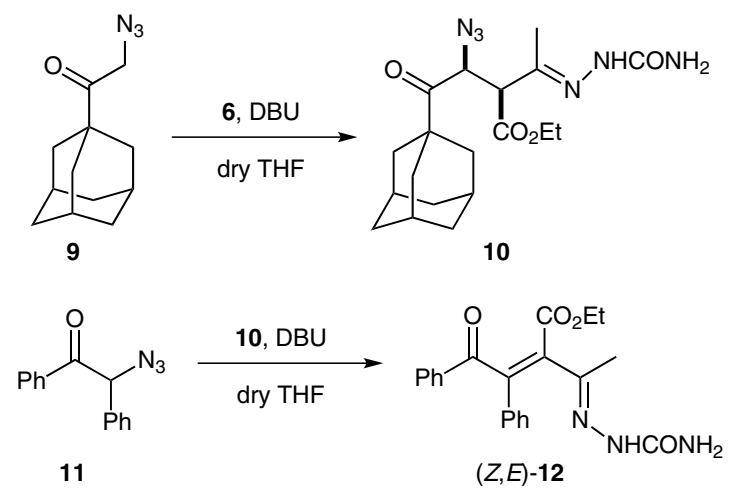

Scheme 3 Reactions of 1-(adamantan-1-yl)-2-azidoethanone (9) and 2-azido-1,2-diphenylethanone (10) with diazadiene 6
We also investigated the reactions of $\alpha$-azido ketones containing $\alpha$-branching. Only the reaction of 2-azido-1,2-diphenylethanone (11) with the diazadiene 6 in the presence of catalytic amounts of DBU resulted in the formation of an elimination product 12 in a low yield (17\%) and in a diastereomerically pure $(Z, E)$ form (Scheme 3$)$. 2-Azidopropiophenone and 3-azidobutane-2-one failed to give any isolable product.

As another point of interest, we also studied the coupling reactions of cyclic $\alpha$-azido ketones. The reactions of 3azidochromanones 13a-c or 3-azido-1-thiochromanone (14a) with diazadiene 6 under our standard conditions (DBU catalysis) gave the desired ethyl 2-(3-azido-4-oxo3,4-dihydro-2H-1-benzopyran-3-yl)-3-[(carbamoylamino)imino]butanoates 16a-c and ethyl 2-(3-azido-4-oxo-3,4dihydro-2H-1-benzothio-pyran-3-yl)-3-[(carbamoylamino)imino]butanoate (21a), respectively, in good to excellent yield (60-93\%) and in diastereopure form (Scheme 4 and Table 2, entries 1-4). In these cases, the Michael adducts were more stable than those of the acyclic acetophenones. In the cases of the 3-azido-6-chlorochromanone (13c) and 3-azido-1-thiochromanone (14a), we also isolated the corresponding chromone $19 \mathrm{c}$ and thiochromone 20a, respectively, but here the elimination of hydrazoic acid affected the heterocyclic ring instead of the aliphatic chain. The driving force for the elimination was, once more, formation of a conjugated system, but the greater stability of the heterocyclic chromone ring affected the regioselectivity. A similar reaction of 2-azidobenzosuberone (15a) with diazadiene 6 led exclusively to ethyl 2\{6-azido-5-oxo-6,7,8,9-tetrahydro-5H-benzo[7]-annulen6-yl\}-3-[(carbamoylamino)imino]-butanoate (18a). Notably, the conversion here was only $77 \%$, despite the longer reaction time $(42 \mathrm{~h})$. In this case, the azide adduct was isolated as a diastereomeric mixture (d.r. $=67: 33$ on the basis of integration of the 4-H hydrogens) (Scheme 4 and Table 2 , entry 5). However, the relative configuration of the diastereomers of $18 \mathbf{a}$ could not be determined.

Table 2 Reactions of Cyclic $\alpha$-Azidoketones 13a-c, 14a, and 15a with Diazadiene 6.

\begin{tabular}{|c|c|c|c|c|c|c|}
\hline Entry & $\begin{array}{l}\text { Starting } \\
\text { material }\end{array}$ & $\mathrm{X}$ & $\mathrm{R}$ & Time (h) & Product(s) & Yield (\%)] \\
\hline 1 & $13 a$ & $\mathrm{O}$ & $\mathrm{H}$ & 0.5 & 16a (93) & - \\
\hline 2 & $13 b$ & $\mathrm{O}$ & $\mathrm{Me}$ & 0.5 & $16 \mathbf{b}(88)$ & - \\
\hline 3 & $13 c$ & $\mathrm{O}$ & $\mathrm{Cl}$ & 0.5 & $16 c(60)$ & $19 \mathrm{c}(9.8)$ \\
\hline 4 & $14 a$ & $\mathrm{~S}$ & $\mathrm{H}$ & 0.5 & $17 \mathbf{a}(79)$ & $\mathbf{2 0 a}(21)$ \\
\hline 5 & $15 a$ & $\left(\mathrm{CH}_{2}\right)_{2}$ & $\mathrm{H}$ & $42^{\mathrm{a}}$ & $18 \mathbf{a}(66)^{b}$ & - \\
\hline
\end{tabular}

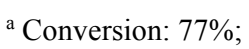

b d.r. $=67: 33$

In conclusion, the reactivity of $\alpha$-azido ketones under basic conditions with a diazadiene as a Michael acceptor has been demonstrated. The successful coupling provides additional examples of the usefulness of $\alpha$-azido ketones as 


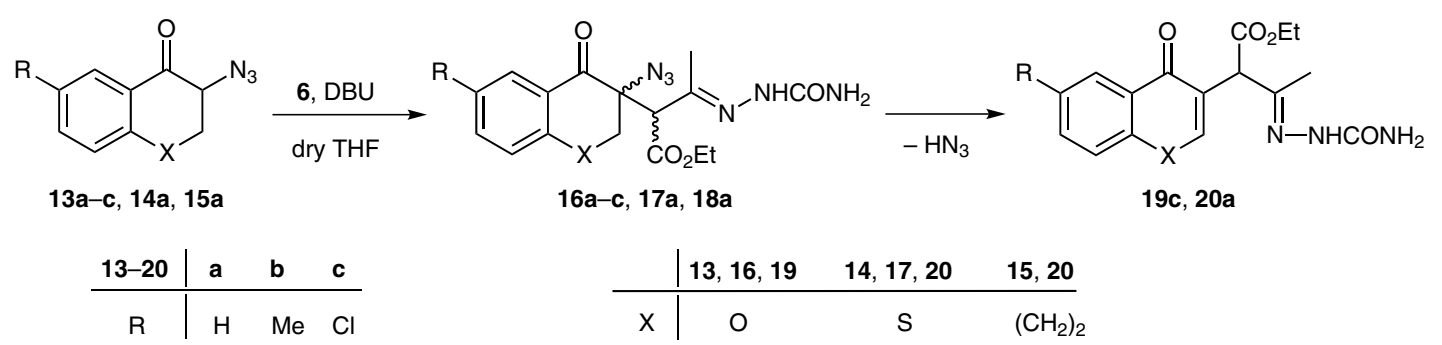

Scheme 4 Reactions of 3-azido(thio)chromanones 13a-c, 14a, and 2-azido-1-benzosuberone (15a) with diazadiene 6

nucleophilic partners in $\mathrm{C}-\mathrm{C}$ bond-forming reactions and of diazadienes as Michael acceptors. Unfortunately, the adducts of acyclic $\alpha$-azido ketones showed limited stability and easily lost hydrazoic acid to give the corresponding 2-\{1-[(carbamoylamino)imino]ethyl $\}-4-o x o-4-p h e n y l-$ but-2-enoates. The more stable adducts obtained from cyclic $\alpha$-azido ketones appear be interesting substrates, and an investigation of their chemistry is still in progress.

\section{Acknowledgment}

Financial support from the Hungarian Scientific Research Fund (OTKA T75806) is highly appreciated. The work was also supported by the TÁMOP 4.2.1./B-09/1/KONV-2010-0007 project. The project is implemented through the New Hungary Development Plan, co-financed by the European Social Fund and the European Regional Development Fund.

Supporting Information for this article is available online at http://www.thieme-connect.com/products/ejournals/journal/ $10.1055 / \mathrm{s}-00000083$

\section{References}

(1) Part 7 was published as: Kónya, K.; Fekete, Sz.; Ábrahám, A.; Patonay, T. Mol. Diversity 2012, 16, 91.

(2) Patonay, T.; Kónya, K.; Juhász-Tóth, É. Chem. Soc. Rev. 2011, 40, 2797.

(3) (a) Langer, P.; Freifeld, I. Chem. Commun. 2002, 2668. (b) Langer, P.; Freifeld, I.; Shojaei, H. Chem. Commun. 2003, 3044. (c) Freifeld, I.; Shojaei, H.; Langer, P. J. Org.
Chem. 2006, 71, 4965. (d) Freifeld, I.; Shojaei, H.; Dede, R.; Langer, P. J. Org. Chem. 2006, 71, 6165.

(4) (a) Patonay, T.; Hoffman, R. V. J. Org. Chem. 1995, 60, 2368. (b) Patonay, T.; Juhász-Tóth, É.; Bényei, A. Eur. J. Org. Chem. 2002, 285. (c) Juhász-Tóth, É.; Patonay, T. Eur. J. Org. Chem. 2002, 3055. (d) Patonay, T.; Jekö, J.; Juhász-Tóth, É. Eur. J. Org. Chem. 2008, 1441.

(5) Padwa, A.; Sá, M. M.; Weingarten, M. D. Tetrahedron 1997, 53, 2371.

(6) Chowdari, N. S.; Ahmad, M.; Albertshofer, K.; Tanaka, F.; Barbas, C. F. III. Org. Lett. 2006, 8, 2839.

(7) Marco, J. L.; Martínez-Grau, A.; Martín, N.; Seoane, C. Tetrahedron Lett. 1995, 36, 5393.

(8) (a) Attanasi, O. A.; Caglioti, L. Org. Prep. Proced. Int. 1986, 18, 299. (b) Attanasi, O. A.; Filippone, P.; SerraZanetti, F. Trends Heterocycl. Chem. 1993, 3, 461.

(c) Attanasi, O. A.; Filippone, P.; Serra-Zanetti, F. Prog. Heterocycl. Chem. 1995, 7, 1. (d) Attanasi, O. A.; Filippone, P. Synlett 1997, 1128. (e) Attanasi, O. A.; De Crescentini, L.; Filippone, P.; Mantellini, F.; Santeusanio, S. ARKIVOC 2002, (xi), 274. (f) Attanasi, O. A.; De Crescentini, L.; Favi, G.; Filippone, P.; Mantellini, F.; Perulli, F. R.; Santeusanio, S. Eur. J. Org. Chem. 2009, 3109.

(9) Kanzian, T.; Nicolini, S.; De Crescentini, L.; Attanasi, O. A.; Ofial, A. R.; Mayr, H. Chem. Eur. J. 2010, 16, 12008.

(10) Crystallographic data for compounds $(Z, E)-\mathbf{8 a}$ and $(E, E)-\mathbf{8 d}$ have been deposited with the accession numbers CCDC 814890 and 814891 , respectively, and can be obtained free of charge from the Cambridge Crystallographic Data Centre, 12 Union Road, Cambridge CB2 1EZ, UK; Fax:+44(1223)336033; E-mail: deposit@ccdc.cam.ac.uk; Web site: www.ccdc.cam.ac.uk/conts/retrieving.html. 
Copyright of Synlett is the property of Georg Thieme Verlag Stuttgart and its content may not be copied or emailed to multiple sites or posted to a listserv without the copyright holder's express written permission. However, users may print, download, or email articles for individual use. 